\title{
Transparente Keramik
}

Um neue Werkstoffe sicher verbinden zu können, bedarf es oft der Einsatzes der Klebtechnik. Vor diesem Hintergrund dürfte auch für Klebtechniker von Interesse sein, dass es dem Keramikhersteller CeramTec jetzt gelungen ist, transparente Keramik im Serienmaßstab herzustellen. Der neue Werkstoff trägt den Namen Perlucor und wurde erstmals auf der Hannover Messe vorgestellt.

Derlucor ist ein hochreiner keramischer Werkstoff mit zahlreichen außergewöhnlichen mechanischen, chemischen, thermischen sowie optischen Eigenschaften. Durch den hohen Transparenzgrad von mehr als 80 Prozent - was einer re-

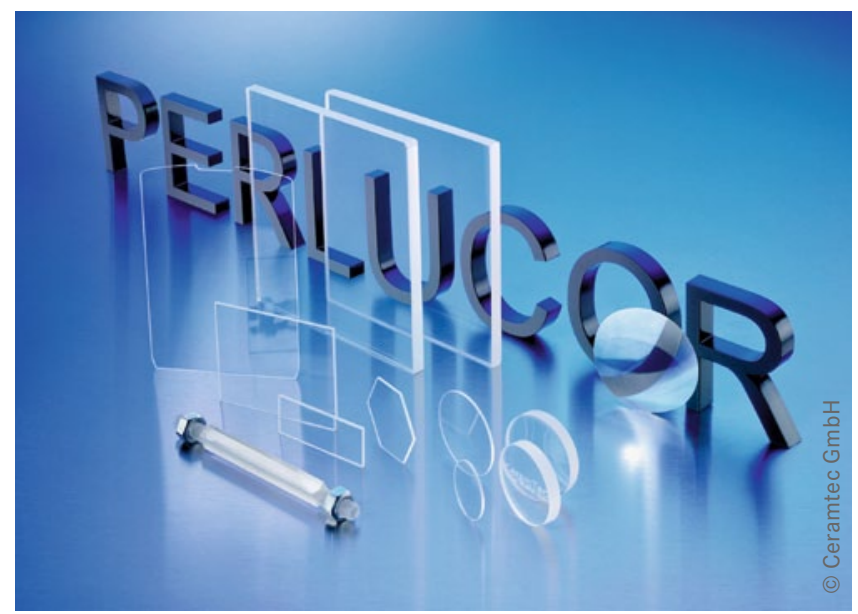

Der Ceramtec $\mathrm{GmbH}$ ist es als erstem europäischen Unternehmen gelungen, die transparente Keramik Perlucor im Serienmaßstab herzustellen.

lativen Transparenz von über 90 Prozent entspricht - ergeben sich für diesen Werkstoff überall dort Anwendungsfelder, wo herkömmliches Glas an seine Grenzen stößt. Neben der hohen Transparenz überzeugt Perlucor auch durch eine enorme Festigkeit und Härte, die die Werte von Glas um das Drei- bis Vierfache überschreiten. Damit ist die transparente Keramik für den Einsatz unter extremen Verschleißbedingungen, etwa im Maschinen-, Anlagen- oder Gerätebau, gut geeignet. Die Entwickler sehen darüber hinaus Applikationsmöglichkeiten in der Medizintechnik sowie in den Bereichen Optik, Architektur, Schmuck und Design.

\section{Thermisch belastbar und chemisch beständig}

Das neue Material besitzt gegenüber Glas eine um den Faktor drei höhere thermische Belastbarkeit. Dies erlaubt den Einsatz bei Temperaturen von bis zu 1.600 Grad Celsius. So kann die transparente Keramik beispielsweise als Sichtfenster in Hochtemperaturöfen verwendet werden. Aufgrund seiner Reinheit weist Perlucor zudem eine einzigartig hohe chemische Beständigkeit auf und ist deshalb auch für Bereiche interessant, in denen mit hochkonzentrierten Säuren und Laugen gearbeitet wird.

Die Standardgröße von Perlucor beträgt 90x90 Millimeter. Aus diesem Format können auch - je nach Kundenspezifikation - Sonderkonturen gefertigt werden. Die Stärke von Perlucor kann individuell auf einen Zehntelmillimeter genau hergestellt werden. Um größere Flächen zu erzeugen, lassen sich die Formen zu Multi-Teil-Verbünden kombinieren. Die Fügekanten werden dann mithilfe eines speziell von CeramTec entwickelten Klebverfahrens so gefügt, dass die Fugen aufgrund des gleichen Brechungsindex von Keramik und Klebstoff nur noch zu erahnen sind und so eine durchgängig transparente Fläche geschaffen wird.

Weitere Infos: www.ceramtec.de

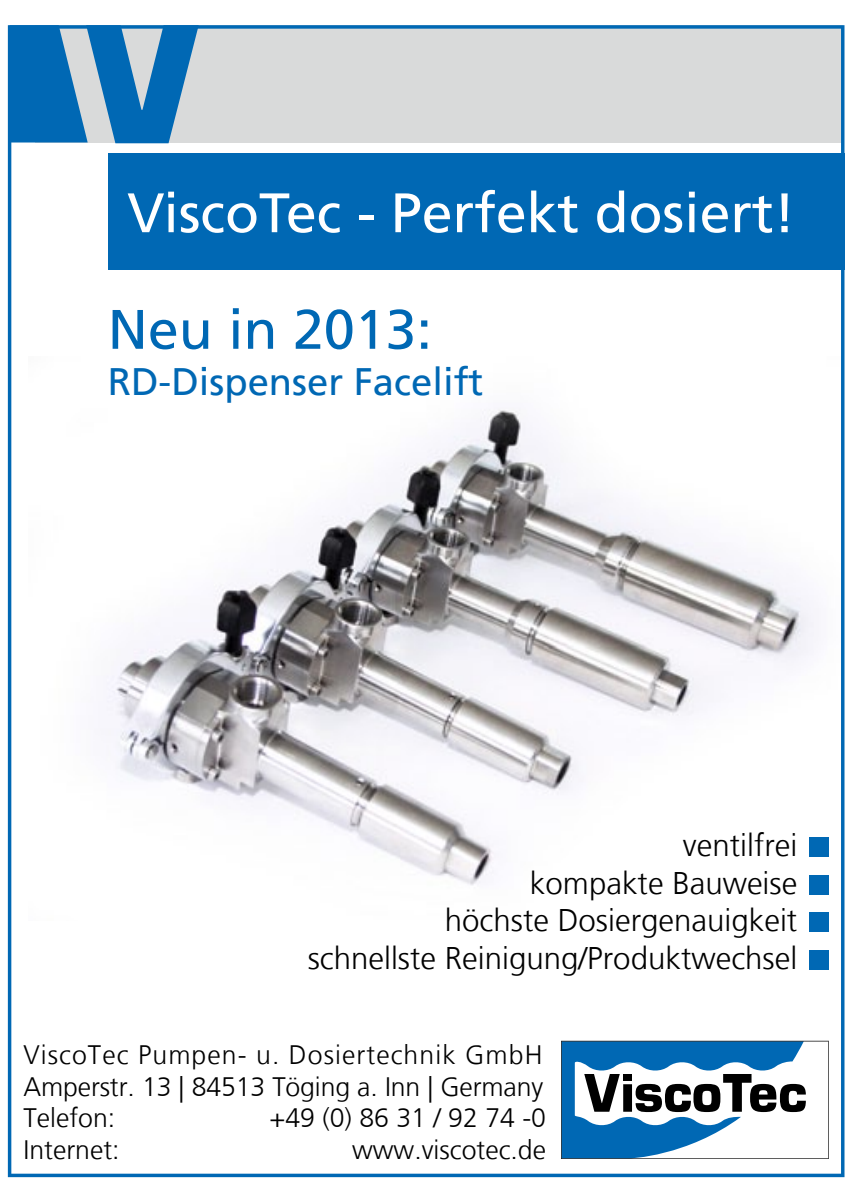

